\title{
Clinical pharmacokinetics and drug exposure-toxicity correlation study of docetaxel based chemotherapy in Chinese head and neck cancer patients
}

\author{
Yuxiang Ma ${ }^{1 \#}$, Qingguang Lin ${ }^{2 \#}$, Yunpeng Yang ${ }^{1 \#}$, Weiting Liang ${ }^{1}$, S. J. Salamone ${ }^{3}$, Yunying Li $^{3}$, Yuehao Lin ${ }^{1}$, \\ Hongyun Zhao ${ }^{1}$, Yuanyuan Zhao ${ }^{1}$, Wenfeng Fang ${ }^{1}$, Yan Huang ${ }^{1}$, Li Zhang ${ }^{1}$ \\ ${ }^{1}$ Department of Medical Oncology, ${ }^{2}$ Department of ultrasonography, Sun Yat-sen University Cancer Center, State Key Laboratory of Oncology in \\ South China, Collaborative Innovation Center for Cancer Medicine, Guangzhou 510060, China; ${ }^{3}$ Saladax Biomedical Inc., Bethlehem, PA, USA \\ Contributions: (I) Conception and design: Y Ma, Q Lin, Y Yang, SJ Salamone, L Zhang; (II) Administrative support: L Zhang; (III) Provision of study \\ materials or patients: Y Ma, Q Lin, Y Yang, H Zhao, Y Zhao, W Fang, Y Huang; (IV) Collection and assembly of data: Y Ma, Q Lin, W Liang; (V) \\ Data analysis and interpretation: Y Ma, Q Lin, SJ Salamone, Y Li, Y Lin; (VI) Manuscript writing: All authors; (VII) Final approval of manuscript: \\ All authors. \\ "These authors contributed equally to this work. \\ Correspondence to: Li Zhang, MD. Professor of Medical Oncology, Sun Yat-sen University Cancer Center, 651\# Dongfeng Road, East, Guangzhou \\ 510060, China. Email: zhangli63@hotmail.com.
}

Background: Area under time-concentration curve (AUC) of docetaxel is related with its toxicity and efficacy. The aim of this study is to investigate the target range of docetaxel AUC in Chinese head and neck cancer (HNC) patients.

Methods: Eligible HNC patients were enrolled and received at least 2 cycles of docetaxel-based chemotherapy. A simplified pharmacokinetic (PK) strategy (2 monitored samples) was developed to simulate docetaxel AUC using the nonlinear mixed-effect modelling program. Preliminary target range of AUC was pre-set as $2.5-3.7 \mu \mathrm{g} \cdot \mathrm{hr} / \mathrm{mL}$ according to pooled analysis from 8 previous studies. Fisher exact test was used to analyze the relationship between AUC with neutropenia and efficacy, and to verify the target range.

Results: Thirty-nine eligible patients were enrolled. Grade 3-4 and grade 4 neutropenia rate in $1^{\text {st }}$ cycle was $64 \%$ and $36 \%$, respectively. AUC simulation by simplified PK strategy was acceptable compared to full sampling method from the analysis of archived 300 patients' data, with $-5.67 \%$ of mean prediction error (MPE). Median AUC of all patients was $2.58 \mu \mathrm{g} \cdot \mathrm{hr} / \mathrm{mL}$ (range from 1.28 to 9.39). A significant correlation $(\mathrm{P}=0.007)$ was detected between AUC and body surface area (BSA)-dosage, but BSA contributed only $18.3 \%$ of AUC inter-individual variability. Docetaxel AUC was significantly related with the severity (grade 3-4) of neutropenia (correlation of coefficient was 0.452 , $\mathrm{P}=0.004)$. Fourteen patients $(36 \%)$ were within the target AUC range. Patients with AUC above the target experienced more severe neutropenia (grade 3-4 rate $100 \%$ vs. $56 \%, \mathrm{P}=0.036$; grade 4 rate $86 \%$ vs. $25 \%, \mathrm{P}=0.005$ ). No significant difference of response rate was found between patients within the target or not.

Conclusions: A simplified samples PK strategy was developed for docetaxel AUC simulation. The target range of docetaxel AUC in Chinese HNC patients was suggested at 2.5-3.7 $\mu \mathrm{g} \cdot \mathrm{hr} / \mathrm{mL}$ for reduced toxicity without compromising efficacy of docetaxel treatment.

Keywords: Docetaxel; area under time-concentration curve (AUC); Chinese; head and neck cancer (HNC); neutropenia

Submitted Aug 25, 2019. Accepted for publication Dec 13, 2019.

doi: $10.21037 /$ atm.2020.01.76

View this article at: http://dx.doi.org/10.21037/atm.2020.01.76 


\section{Introduction}

Docetaxel is a commonly used anti-neoplastic agent of the taxoid family with broad activity in a variety of solid tumors, such as breast, non-small-cell lung, head and neck, ovarian, and prostate cancers (1). As with most cytotoxic agents, docetaxel has a narrow therapeutic window $(2,3)$. Notably, severe hematologic toxicity, mostly neutropenia, is the major dose limiting side effect of docetaxel, especially for short courses of treatment, such as induction chemotherapy in head and neck cancer (HNC) (4-7).

Traditionally, the dosage of docetaxel has been based on body surface area (BSA), which is believed to reduce the inter-patient variability of drug exposure (8). However, previous studies have indicated that BSA had a limited effect on predicting drug clearance, and only 15-35\% of metabolic variability could be accounted for by BSA adjusted dosing $(9,10)$. Rudek demonstrated a $35 \%$ coefficient of variation (CV) in clearance when docetaxel was administered in six different regimens. Normalization of clearance based on BSA reduced the variation by only $1.7 \%$ in this study (11).

The most important limitation of docetaxel treatment is its unpredictable toxicity due to large inter-individual variability of drug exposure based on BSA dosing (12-14). The large PK variability could result in a proportion of patients being under-dosed, resulting in lower efficacy, or overdosed, resulting in increased toxicity (13). Previous studies have indicated that docetaxel exposure measured by area under time-concentration curve (AUC) was significantly correlated with its toxicity (mainly neutropenia) $(5,15-21)$. Bruno's researches in 640 Caucasian patients demonstrated a positive correlation between AUC and grade 4 neutropenia and febrile neutropenia (16). A change in AUC from 4.2 to $6.5 \mu \mathrm{g} \cdot \mathrm{hr} / \mathrm{mL}$ was predictive of an approximate 2 -fold increase in the odds of severe adverse events (AEs). In Asian population, Goh and Minami's researches also demonstrated a similar relationship between AUC and reduction in absolute neutrophil count $(5,17)$.

The standard dosage of docetaxel in Caucasian populations is 75 to $100 \mathrm{mg} / \mathrm{m}^{2}$. The previous research by Engels suggest the target AUC values are 3.68 and $4.90 \mu \mathrm{g} \cdot \mathrm{hr} / \mathrm{mL}$ for 75 and $100 \mathrm{mg} / \mathrm{m}^{2}$, respectively (21). However, the dosage of docetaxel for Chinese patients is generally lower $\left(60 \mathrm{mg} / \mathrm{m}^{2}\right)$ because of higher hematological toxicity than Caucasian population $(22,23)$. No optimal AUC range has been established in Chinese populations $(5,15-21)$. Therefore, the objectives of this study are to analyze the correlation of AUC and neutropenia or efficacy in docetaxel chemotherapy and to find the optimal target AUC range in Chinese HNC patients.

\section{Methods}

\section{Patients}

This trial was conducted between January 2013 and June 2014 (data cutoff). Eligibility criteria included (I) 18-75 years old, (II) no history of systemic chemotherapy, and (III) diagnosis with pathologically confirmed HNC, (IV) indication for docetaxel based systemic chemotherapy, (V) an Eastern Cooperative Oncology Group performance score of $0-1$, and (VI) at least one lesion measurable by CT scan or MRI according to Response Evaluation Criteria In Solid Tumors (RECIST v1.1). Patient screening was conducted at the Sun Yat-sen University Cancer Center (SYSUCC) and conducted in accordance with the principles of the Declaration of Helsinki and the Good Clinical Practice Guidelines of the International Conference on Harmonization. The study was approved by the Ethical Committee of SYSUCC (B2013-008-01). Written informed consent was obtained for each patient individually prior to enrollment in the study. This trial was registered at clinicaltrials.gov (NCT01891123).

\section{Study design}

Eligible patients were enrolled and received at least 2 cycles of docetaxel-platinum double or plus 5-Fu triple regimens, platinum was chosen from cisplatin or carboplatin according to investigator. In this 3 -weekly regimen, docetaxel was administrated at a dose of $60 \mathrm{mg} / \mathrm{m}^{2}$ by intravenous infusion after standard premedication for $1.5 \mathrm{~h}$ (infusion started around 10-11 am), followed by cisplatin at a dose level of $60 \mathrm{mg} / \mathrm{m}^{2}$ (or carboplatin at dose of AUC 5) by intravenous infusion. 5-fluorouracil was transfused afterwards by constant speed continuous intravenous infusion for $120 \mathrm{~h}$ at a dose level of $3 \mathrm{~g} / \mathrm{m}^{2}$ (infusion started around 3-4 pm). Primary G-CSF prophylaxis was not permitted in the first cycle, but allowed in subsequent cycles. Patients experiencing grade 4 neutropenia or febrile neutropenia were allowed to receive therapeutic G-CSF treatment. The primary endpoint of this trial was toxicity (mainly neutropenia) after 1 cycle, and the secondary endpoint was efficacy after 2 cycles. This study was discontinued after 2 cycles of chemotherapy, whether patients still receive 
further cycles of docetaxel regimen chemotherapy or turn to other treatment was determined by investigators.

\section{Toxicity and response assessment}

AEs were assessed and documented by investigators according to the National Cancer Institute's Common Terminology Criteria for Adverse Events (CTCAE) v4.03. For neutropenia, grade $0-2$ was considered moderate, 3-4 was considered severe, according to national comprehensive cancer network (NCCN) guideline for hematopoietic growth factors. Patients were evaluated for safety by laboratory tests and physical examination. To determine the severity of neutropenia, a recommended plan of additional peripheral complete blood count tests was set at days 5, 8, 11, 14, 17 and 20 after each chemotherapy cycle. Tumor imaging was performed at screening and after $2^{\text {nd }}$ cycle using either CT scan or MRI, and assessed by investigators according to RECIST v1.1.

\section{Pharmacokinetic (PK)}

Two peripheral blood samples were collected in first cycle of chemotherapy. The feasibility of a limited sampling strategy with only two monitored samples has been shown (24). In this trial, two monitored samples at end of infusion (EOI) and $1 \mathrm{~h}$ after EOI were collected and centrifuged within 2 hours, and the plasma was separated and frozen at $-80^{\circ} \mathrm{C}$ for PK analysis of docetaxel levels at the Sun Yat-sen University Cancer Center laboratory. The concentration of docetaxel in plasma was determined utilizing the MyDocetaxel ${ }^{\mathrm{TM}}$ Assay (Saladax Biomedical Inc., Bethlehem, PA, USA), an automated homogeneous two-reagent nanoparticle agglutination immunoassay for the detection of docetaxel in human plasma (25). AUC was calculated using the nonlinear mixed-effect modelling program (NONMEM) version $\mathrm{V}$ (double precision, level 1.1) using previously validated PK parameters (16) and the published residual variability (24).

\section{Preliminary determination of target AUC from pooled 8 docetaxel PK studies}

Before the PK analysis of this trial, a systemic literature survey was performed using PubMed (Table 1). Relevant publications reporting docetaxel PKs and toxicity or efficacy were retrieved. Twenty-two studies were included, 7 were excluded for lacking of AUC data (26-32), 3 were excluded for the lack of toxicity data (neutropenia) (33-35), 2 were excluded for liver disfunction enrollment $(36,37)$, and 2 were excluded for the lack of correlation analysis $(38,39)$. Totally, 8 studies were enrolled into this pooled analysis $(5,15-21)$. Two studies in Caucasian populations have indicated that a docetaxel dosage of $100 \mathrm{mg} / \mathrm{m}^{2}$ leads to a median AUC of about 4.81-5.62 $\mu \mathrm{g} \cdot \mathrm{hr} / \mathrm{mL}$, such high docetaxel AUC also lead to severe hematologic toxicities $(16,18)$. The reported grade 4 neutropenia rate was $64 \%$, and $>90 \%$ decrease rate of ANC in total courses. The suggested target AUC of $75 \mathrm{mg} / \mathrm{m}^{2}$ dosage from Engel's research on Caucasian population was $3.68 \mu \mathrm{g} \cdot \mathrm{hr} / \mathrm{mL}$ (21). However, the same dosage of docetaxel in Asian population leads to an average AUC of $5.1 \mu \mathrm{g} \cdot \mathrm{hr} / \mathrm{mL}$, also with $74 \%$ rate of grade 3 or 4 neutropenia rate according to Goh's research (17). Two Japanese studies show that the median docetaxel AUC with an acceptable toxicity, which is $34.8 \%$ grade 4 neutropenia rate or $4.5 \%$ febrile neutropenia rate, is around $2.68-3.03 \mu \mathrm{g} \cdot \mathrm{hr} / \mathrm{mL}$ with a lower dosage at $60 \mathrm{mg} / \mathrm{m}^{2}(5,20)$.

An optimal AUC range from previous studies was set at $2.5-3.7 \mu \mathrm{g} \cdot \mathrm{hr} / \mathrm{mL}$ accordingly. The upper limit at $3.7 \mu \mathrm{g} \cdot \mathrm{hr} / \mathrm{mL}$ was set as the suggested target AUC in Baker's research (18), the lower limit at $2.5 \mu \mathrm{g} \cdot \mathrm{hr} / \mathrm{mL}$ was set as the median AUC in neutropenia grade 1-3 patients according to Minami's research (5). Based on the data from 3 previously reported docetaxel PK studies in Asian populations $(5,17,20)$, the estimated neutropenia rates within the pre-set optimal AUC range (2.5-3.7 $\mu \mathrm{g} \cdot \mathrm{hr} / \mathrm{mL})$ were moderate and tolerable, with grade 3-4 neutropenia around $50-70 \%$ and grade 4 neutropenia around $20-40 \%$.

\section{Statistics}

Descriptive statistics for quantitative variables, such as means, standard deviations, medians, and percent coefficients of variation (\% CV), and counts and proportions for categorical variables were calculated and listed. Pairwise spearman rank correlation between docetaxel AUC values and neutropenia grades were performed to determine the correlation coefficient and significance level. Scatter plots were presented to graphically describe the relationship of BSA adjusted dosages and AUC, and simple linear regression analysis was also conducted. Fisher's exact test was utilized to compare the proportions of neutropenia grades and efficacy among patients with different docetaxel AUC grouped by pre-set AUC range. Sample size was calculated by estimated the grade 3-4 neutropenia rate 
Table 1 The basic information and the results of AUC-outcome analysis from pooled 8 docetaxel pharmacokinetic studies

\begin{tabular}{|c|c|c|c|c|c|c|}
\hline Study & Population & Indication & Number & $\begin{array}{l}\text { Regimen dosage } \\
\qquad(\mathrm{Q} 3 \mathrm{~W})\end{array}$ & AUC $\mu \mathrm{g} \cdot \mathrm{hr} / \mathrm{mL}$ & Outcomes \\
\hline $\begin{array}{l}\text { Extra } \\
1993(15)\end{array}$ & Not mentioned & $\begin{array}{l}\text { Solid tumors (OC, } \\
\text { BC, SCLC, etc.) }\end{array}$ & 23 & $20-115 \mathrm{mg} / \mathrm{m}^{2}$ & $\begin{array}{l}2.79 \pm 0.85 \text { for } \\
70 \mathrm{mg} / \mathrm{m}^{2}\end{array}$ & $\begin{array}{l}\text { Grade } 4 \text { neutropenia is } 57 \% \text { in } \geq 85 \mathrm{mg} / \mathrm{m}^{2} \\
\text { (AUC } 4.10-5.93 \text { ), and } 16 \% \text { in } 70 \mathrm{mg} / \mathrm{m}^{2} \text {; } \\
\text { AUC correlated with the percentage } \\
\text { decrease of neutrophils }\end{array}$ \\
\hline $\begin{array}{l}\text { Bruno, } \\
1998 \text { (16) }\end{array}$ & $\begin{array}{l}\text { Mostly } \\
\text { Caucasian }\end{array}$ & $\begin{array}{l}\text { Breast cancer, } \\
\text { non-small cell } \\
\text { lung cancer }\end{array}$ & 640 & $\begin{array}{l}640\left(5 \% 75 \mathrm{mg} / \mathrm{m}^{2},\right. \\
\left.95 \% 100 \mathrm{mg} / \mathrm{m}^{2}\right)\end{array}$ & $\begin{array}{l}4.81 \text { median } \\
(2.93-9.52) \text { for all }\end{array}$ & $\begin{array}{l}\text { Severe hematologic toxicity, with } 64 \% \\
\text { grade } 4 \text { neutropenia. AUC is a strong } \\
\text { predictor of neutropenia }(P<0.0001), 4.8 \text { as } \\
\text { threshold; AUC at first cycle is a significant } \\
\text { predictor of time to progression }\end{array}$ \\
\hline $\begin{array}{l}\text { Goh, } \\
2002 \text { (17) }\end{array}$ & Asian & $\begin{array}{l}\text { Solid tumor } \\
\text { indicated for } \\
\text { docetaxel }\end{array}$ & 31 & $\begin{array}{l}75 \mathrm{mg} / \mathrm{m}^{2}(\mathrm{~N}=23) \\
100 \mathrm{mg} / \mathrm{m}^{2}(\mathrm{~N}=8)\end{array}$ & $5.1 \pm 1.6 ; 5.5 \pm 1.6$ & $\begin{array}{l}\text { Grade } 3 \text { or } 4 \text { neutropenia rates are } 74 \% \\
(17 / 23) \text { and } 63 \%(5 / 8) \text { in } 75 \text { and } \\
100 \mathrm{mg} / \mathrm{m}^{2} \text {, respectively; AUC significant } \\
\text { correlated with ANC nadir }(P=0.001)\end{array}$ \\
\hline $\begin{array}{l}\text { ten Tije, } \\
2005 \text { (19) }\end{array}$ & $\begin{array}{l}\text { Mostly } \\
\text { Caucasian }\end{array}$ & $\begin{array}{l}\text { Histologically } \\
\text { confirmed solid } \\
\text { tumor }\end{array}$ & 51 & $\begin{array}{l}75 \mathrm{mg} / \mathrm{m}^{2}, 1 \text { hour } \\
\text { infusion every } \\
3 \text { weeks }\end{array}$ & $\begin{array}{l}\text { Age }<65=5.69 \\
\text { age } \geq 65=6.01\end{array}$ & $\begin{array}{l}\text { Grade } 4 \text { neutropenia; age }<65=30 \% ; \\
\text { Age } \geq 65=63 \% \text {; febrile neutropenia; } \\
\text { age }<65=0 \% \text {; age } \geq 65=16 \%\end{array}$ \\
\hline $\begin{array}{l}\text { Minami, } \\
2006 \text { (5) }\end{array}$ & Asian & $\begin{array}{l}\text { Solid tumors (BC, } \\
\text { NSCLC, HNC, } \\
\text { et al.) }\end{array}$ & 69 & $\begin{array}{l}60 \mathrm{mg} / \mathrm{m}^{2} \text { (range, } \\
20-60)\end{array}$ & $\begin{array}{l}\text { Median } 2.68 \\
\text { (range, } 1.35-12.20)\end{array}$ & $\begin{array}{l}\text { Toxicity: } 34.8 \% \text { patients }(24 / 69) \\
\text { experienced grade } 4 \text { neutropenia, efficacy } \\
\text { data not mentioned; median AUC with } \\
\text { neutrophils }<500=2.73 \text {, range, } 1.49 \text { to } \\
5.99 \text {; median } A U C \text { with neutrophils } \geq 500 \\
=2.49 \text {, range, } 1.35 \text { to } 12.17\end{array}$ \\
\hline $\begin{array}{l}\text { Engels, } \\
2011(21)\end{array}$ & Caucasian & $\begin{array}{l}\text { Solid tumors } \\
\text { indicated for } \\
\text { docetaxel }\end{array}$ & 30 & $\begin{array}{l}\text { Mostly } 100 \mathrm{mg} / \mathrm{m}^{2} \\
\text { (decreased dosage } \\
75 \mathrm{mg} / \mathrm{m}^{2} \text { ) }\end{array}$ & $\begin{array}{l}\text { Target } 4.90 \text { for } \\
100 \mathrm{mg} / \mathrm{m}^{2} \text {; target } \\
3.68 \text { for } 75 \mathrm{mg} / \mathrm{m}^{2}\end{array}$ & $\begin{array}{l}\text { Severe hematologic toxicity, with }>90 \% \\
\text { decrease rate of ANC in total courses; } \\
\text { PK-guided dosing decreased the inter- } \\
\text { individual variability of percentage } \\
\text { decrease in WBC and ANC }\end{array}$ \\
\hline
\end{tabular}

AUC, area under time-concentration curve; Q3W, every 3 weeks; OC, ovarian cancer; BC, breast cancer; SCLC, small cell lung cancer; ANC, absolute neutrophil count; HNC, head and neck cancer; GC, gastric cancer; CRC, colorectal cancer; NPC, nasopharyngeal carcinoma; FN, febrile neutropenia; PK, pharmacokinetics; WBC, white blood cell.

above target limit $(75 \%)$ versus below target limit $(35 \%)$ from literature review, with type I error 0.05 and type II error 0.2. All statistical analyses were performed using Stata v13.1 (Stata Corp LP, College Station, TX, USA). A significance level of $\mathrm{P}<0.05$ (two-sided) was considered to be statistically significant.

\section{Results}

\section{Patient characteristics and results}

Thirty-nine eligible patients (38 nasopharyngeal carcinoma and 1 tongue carcinoma) were enrolled in this study (Figure 1). Thirty-seven patients received a triple-agent 
Preset the optimal Docetaxel AUC target range for Chinese in literature review

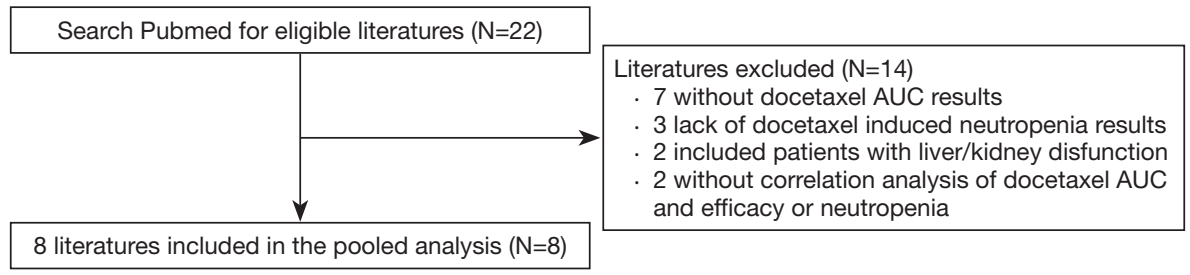

Preset the optimal Docetaxel AUC target range for Chinese in literature review

\begin{tabular}{|c|c|c|}
\hline \multicolumn{2}{|c|}{ Patients screened for eligibility $(\mathrm{N}=46)$} & \\
\hline \multicolumn{2}{|c|}{$\downarrow$} & $\begin{array}{c}\text { Retreated consent }(\mathrm{N}=2) \\
\text { Did not meet the inclusion/exclusion criterion }(\mathrm{N}=5)\end{array}$ \\
\hline \multicolumn{3}{|c|}{$\begin{array}{c}\text { Received at least } 2 \text { cycles of treatment }(\mathrm{N}=39) \\
\text { Did not received at least } 2 \text { cycles of treatment }(\mathrm{N}=0)\end{array}$} \\
\hline$\downarrow$ & & $\begin{array}{l}\text { Efficacy analysis set }(\mathrm{N}=37) \\
\cdot 2 \text { not evaluable according to RECIST vl.I after } 2 \\
\text { cycles chemotherapy } \\
\text { Toxicity analysis set }(\mathrm{N}=39)\end{array}$ \\
\hline Pharmacogenomic & analysis set $(\mathrm{N}=39)$ & \\
\hline
\end{tabular}

Figure 1 Patients' flowchart and study design.

chemotherapy regimen (docetaxel, plus cisplatin, plus 5 -Fluorouracil), and most of the patients were male and with measurable lesions in the local nasopharynx or regional lymph nodes. The detailed characteristics are shown in Table 2. All patients received docetaxel treatment at a dosage of approximately $60 \mathrm{mg} / \mathrm{m}^{2}$. The incident rates of grade 3 and 4 neutropenia rate were $28 \%$ and $36 \%$, respectively. Nineteen patients achieved partial remission (PR) (49\%), 17 patients achieved stable disease (SD) (44\%), and only 1 patient had disease progression after treatment (Table 2).

\section{The verification of two samples simplified PK methods}

Baille's research have shown that with only two monitored samples (first at EOI, and second at 6 hours after EOI), an accurate AUC could be simulated (24). We conducted a PK simulation analysis using archived data base of 300 patients taking one sample at the EOI and the second sample from 0.25 to $5 \mathrm{~h}$ after the EOI compared to full sampling method (start of infusion $0,0.25,0.5 \mathrm{~h}$, EOI 0, 0.25, 0.5, 0.75, 1, 2, $3,4,5,7,9,11,23 \mathrm{~h})$. The results were shown in Table 3. As compared to full sampling method, two samples AUC simulation with EOI time-point and 0.25 to 5 hours after EOI time-point showed satisfactory results. The mean prediction error (MPE) and root mean square error (RMSE) range from $-1.03 \%$ to $-5.70 \%$ and $11.07 \%$ to $17.28 \%$, respectively. For the record, Baille's results showed that two sample with EOI+6 hours were $1.37 \%$ and $12.3 \%$ for
MPE and RMSE respectively, RMSE less than 20\% was considered good (24). With the relatively satisfactory and clinical practical two samples AUC simulation strategy, this trial collected the end of docetaxel infusion and 1 hour after EOI samples (MPE -5.67\% and RMSE 15.67\%).

\section{PK results}

At the dose level of $60 \mathrm{mg} / \mathrm{m}^{2}$, the median docetaxel AUC of all 39 patients was $2.58 \mu \mathrm{g} \cdot \mathrm{hr} / \mathrm{mL}$ (95\% CI, 2.38-3.34), range from 1.28 to 9.39 , and median value was within the preliminary target range. The $\mathrm{CV}$ in cycle 1 was $52 \%$. Seven patients (18\%) with an AUC higher than the upper limit of target range, 14 patients (36\%) in the target range, and 18 patients (46\%) were below the lower limit of the target range (Figure 2).

A scatter plot of dosages adjusted by BSA and docetaxel AUC is presented in Figure 3. As shown, the regression analysis showed that the BSA adjusted dosage was significantly related with docetaxel AUC, with a regression coefficient of 0.328 and a $\mathrm{P}$ value of 0.007 . However, the $\mathrm{R}^{2}$ value was low, and the adjusted effect by BSA contributed only $18.3 \%$ of the inter-individual variability of the docetaxel AUC.

\section{The relationship of AUC and toxicity and efficacy}

The rate of grade 3-4 and 4 neutropenia in all 39 patients 
Table 2 Patients' demographics and clinical characteristics (N=39)

\begin{tabular}{|c|c|}
\hline Characteristic & Patients, N (\%) \\
\hline Age (years, range) & 49 [22-72] \\
\hline \multicolumn{2}{|l|}{ Sex } \\
\hline Male & 32 [82] \\
\hline Female & $7[18]$ \\
\hline \multicolumn{2}{|l|}{ Disease } \\
\hline Nasopharyngeal carcinoma & 38 [97] \\
\hline Tongue carcinoma & $1[3]$ \\
\hline \multicolumn{2}{|c|}{ Dose per body surface area $\left(\mathrm{mg} / \mathrm{m}^{2}\right)$} \\
\hline $55-60$ & $30[77]$ \\
\hline $60-62$ & 9 [23] \\
\hline \multicolumn{2}{|l|}{ ECOG performance status } \\
\hline 0 & $35[90]$ \\
\hline 1 & $4[10]$ \\
\hline \multicolumn{2}{|l|}{ Stage (AJCC 8th) } \\
\hline II & $2[5]$ \\
\hline III & $21[54]$ \\
\hline IV & $16[41]$ \\
\hline \multicolumn{2}{|l|}{ Site of lesion (measurable) } \\
\hline Local nasopharynx & 24 [62] \\
\hline Regional lymph nodes & $30[77]$ \\
\hline Remote lymph node & $6[15]$ \\
\hline Lung & $3[8]$ \\
\hline Liver & $3[8]$ \\
\hline Others & $2[5]$ \\
\hline \multicolumn{2}{|l|}{ Treatment setting } \\
\hline Induction & $31[79]$ \\
\hline Palliative & 8 [21] \\
\hline \multicolumn{2}{|l|}{ Combination chemotherapy } \\
\hline Cisplatin $+5-\mathrm{Fu}$ & 37 [95] \\
\hline Cisplatin & $1[3]$ \\
\hline Carboplatin & $1[3]$ \\
\hline \multicolumn{2}{|c|}{ Neutropenia (assessed by CTC AE v4.03) } \\
\hline Grade $0-2$ & $14[36]$ \\
\hline Grade 3 & $11[28]$ \\
\hline Grade 4 & $14[36]$ \\
\hline
\end{tabular}

Table 2 (continued)
Table 2 (continued)

\begin{tabular}{|c|c|}
\hline Characteristic & Patients, N (\%) \\
\hline \multicolumn{2}{|c|}{ Objective response rate (assessed by RECIST v1.1) } \\
\hline PR & 19 [49] \\
\hline SD & $17[44]$ \\
\hline PD & $1[3]$ \\
\hline NE & $2[5]$ \\
\hline \multicolumn{2}{|c|}{$\begin{array}{l}\text { ECOG, Eastern Cooperative Oncology Group; AJCC, American } \\
\text { Joint Committee on Cancer; CTC AE, Common Terminology } \\
\text { Criteria for Adverse Events; RECIST, Response Evaluation } \\
\text { Criteria in Solid Tumors; PR, partial remission; SD, stable } \\
\text { disease; PD, progressive disease; NE, not evaluable. }\end{array}$} \\
\hline
\end{tabular}

was $64 \%$ and $36 \%$. The distribution of AUC's in cycle 1 by different grades of neutropenia showed that as the AUC increased, the neutropenia became more severe (Figure 4). The median AUC in grade 4 and 3 neutropenia patients were 3.17 and $2.60 \mu \mathrm{g} \cdot \mathrm{hr} / \mathrm{mL}$, in grade 2 and 1 were 2.04 and $1.83 \mu \mathrm{g} \cdot \mathrm{hr} / \mathrm{mL}$. The average AUC in patients experience severe neutropenia (grade 3-4) was significant higher than those with moderate neutropenia (grade $0-2)$, which was 3.23 vs. $2.21 \mu \mathrm{g} \cdot \mathrm{hr} / \mathrm{mL}(\mathrm{P}=0.038)$. The correlation analysis indicated a significant relationship between docetaxel AUC and neutropenia ( $\mathrm{P}$ value $=0.004$, correlation coefficient $=0.452$ ). However, no statistically difference was found between the average AUC of patients achieved PR $(2.64 \mu \mathrm{g} \cdot \mathrm{hr} / \mathrm{mL})$ and average AUC of patients with SD or PD $(3.16 \mu \mathrm{g} \cdot \mathrm{hr} / \mathrm{mL}), t$-test $\mathrm{P}$ value 0.304 .

The correlation analysis of docetaxel AUC, neutropenia, and efficacy is presented in Figure 5. Using the preliminary target AUC range, patients were grouped by the upper and lower limits according to their docetaxel AUC value in cycle 1. Patients with docetaxel AUC above $3.7 \mu \mathrm{g} \cdot \mathrm{hr} / \mathrm{mL}$ experienced more severe neutropenia (grade $3-4$ rate $100 \%$ vs. $56 \%, \mathrm{P}=0.036$; grade 4 rate $86 \%$ vs. $25 \%, \mathrm{P}=0.005)$ than patients with docetaxel AUC under $3.7 \mu \mathrm{g} \cdot \mathrm{hr} / \mathrm{mL}$. Four patients (10\%) received a docetaxel dose reduction at cycle 2 ( $20 \%$ off compared to cycle 1$)$ due to hematological toxicities, 3 patients experienced grade 4 neutropenia, 1 patient experienced grade 3 neutropenia and related fever. Three of them were with docetaxel AUC above target, 1 was within the target. No significant differences in response rate was found between patients with AUC above and below $2.5 \mu \mathrm{g} \cdot \mathrm{hr} / \mathrm{mL}(50 \%$ vs. $53 \%, \mathrm{P}=1.000)$, or above and below $3.7 \mu \mathrm{g} \cdot \mathrm{hr} / \mathrm{mL}(43 \%$ vs. $53 \%, \mathrm{P}=0.693)$. 
Table 3 simulation of AUC according to two samples strategy (EOI and time-point after EOI) compared to full sampling method

\begin{tabular}{|c|c|c|c|c|c|c|c|}
\hline Compare & Full sampling & $\mathrm{EOI}+0.25 \mathrm{~h}$ & $\mathrm{EOI}+0.5 \mathrm{~h}$ & $\mathrm{EOI}+0.75 \mathrm{~h}$ & $\mathrm{EOI}+1 \mathrm{~h}$ & $\mathrm{EOI}+5 \mathrm{~h}$ & $\mathrm{EOI}+6 \mathrm{~h}$ Baille $(25)$ \\
\hline Bias absolute & Median error (h) & -0.09 & -0.11 & -0.15 & -0.17 & -0.02 & NA \\
\hline \multirow[t]{2}{*}{ Bias relative } & MPE (\%) & $-5.13 \%$ & $-5.38 \%$ & $-5.70 \%$ & $-5.67 \%$ & $-1.03 \%$ & $1.37 \%$ \\
\hline & Median error (\%) & $-2.97 \%$ & $-3.31 \%$ & $-4.67 \%$ & $-4.91 \%$ & $-0.74 \%$ & NA \\
\hline $\begin{array}{l}\text { Precision } \\
\text { absolute }\end{array}$ & Absolute median error (h) & 0.27 & 0.23 & 0.25 & 0.24 & 0.21 & NA \\
\hline \multirow[t]{2}{*}{ Precision relative } & RMSE (\%) & $17.28 \%$ & $16.50 \%$ & $15.88 \%$ & $15.67 \%$ & $11.07 \%$ & $12.3 \%$ \\
\hline & Absolute median error (\%) & $8.37 \%$ & $7.00 \%$ & $7.82 \%$ & $7.67 \%$ & $6.49 \%$ & NA \\
\hline
\end{tabular}

AUC, area under time-concentration curve; EOI, end of infusion; MPE, mean prediction error; RMSE, root mean square error; NA, not applicable.

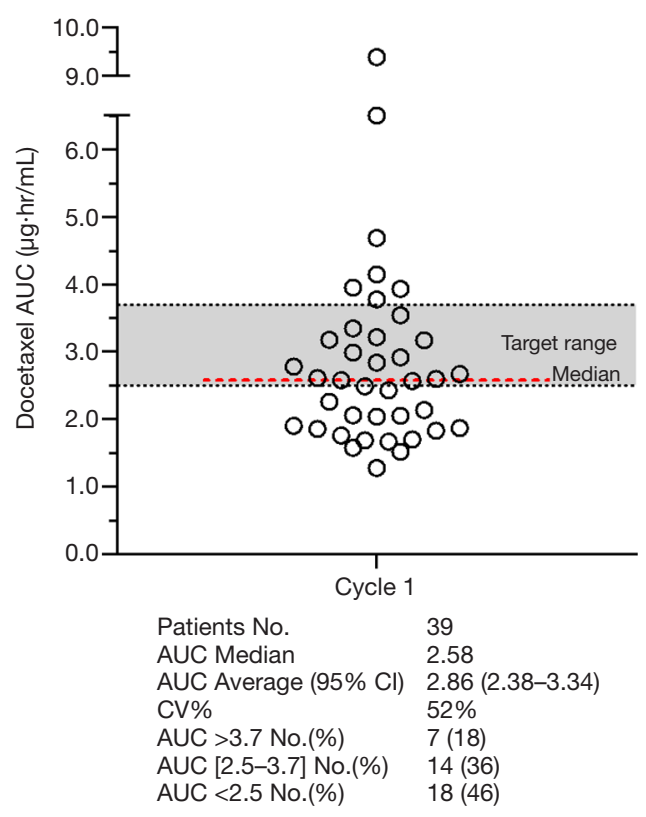

Figure 2 The distribution and descriptive statistics of docetaxel AUC of all patients $(\mathrm{N}=39)$.

\section{Discussion}

The current study examines the population PKs of docetaxel based chemotherapy and analyzed the exposureneutropenia relationship of docetaxel in Chinese patients. Thirty-nine patients with HNC were enrolled and a limited-sample strategy (2 samples) was performed for the calculation of docetaxel AUC by NONMEM (24). The optimal target of AUC for Chinese HNC population was suggested as $2.5-3.7 \mu \mathrm{g} \cdot \mathrm{hr} / \mathrm{mL}$.

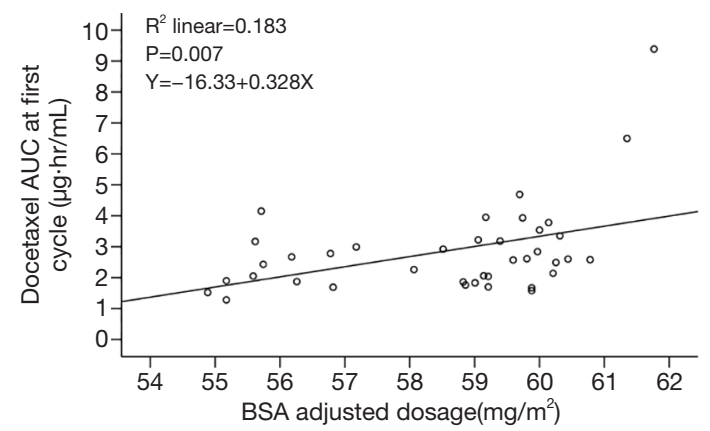

Figure 3 The scatter plot and best fitted line of Docetaxel AUC and BSA adjusted dosage in first cycle.

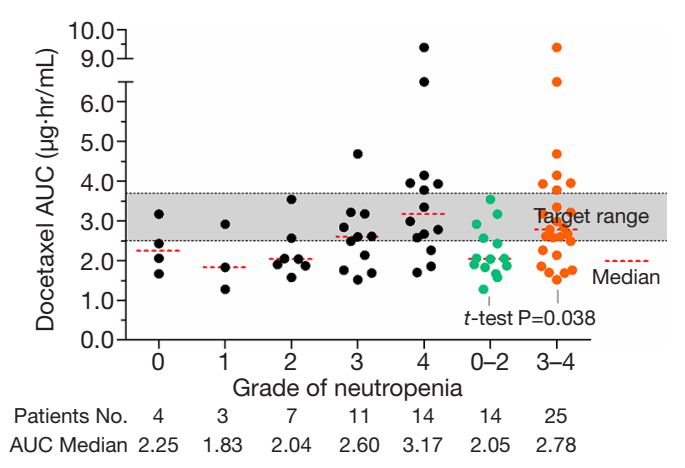

Figure 4 The scatter plot of docetaxel AUC and neutropenia grade in first cycle.

Our study indicated that variability of docetaxel exposure by BSA based dose determination is substantial (over 7-fold). BSA adjustment contributed only $18.3 \%$ of the interindividual variability of docetaxel AUC. Correlation analysis 

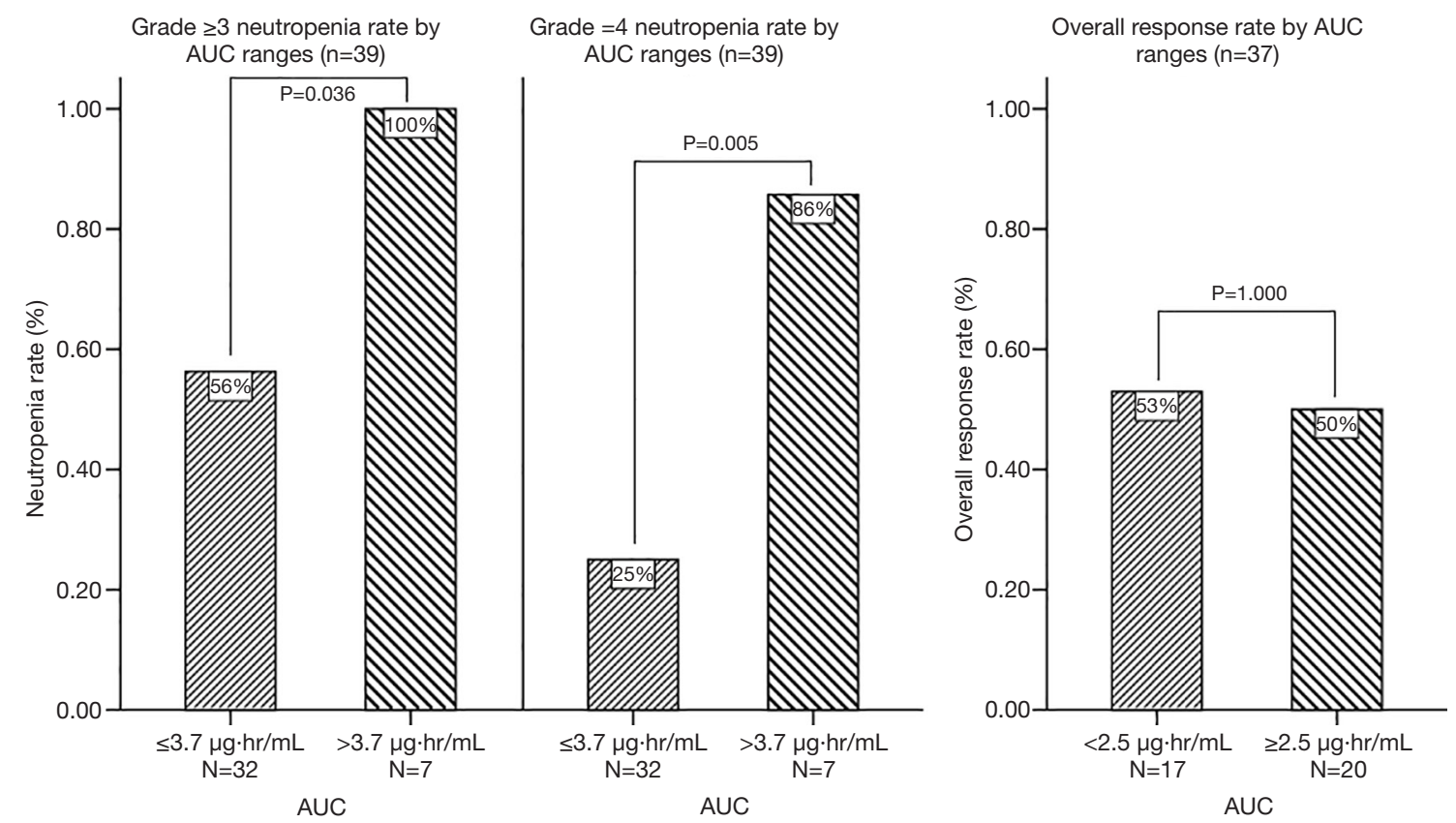

Figure 5 Correlation analysis of 1 st cycle Docetaxel AUC, neutropenia rate, and overall response rate.

in this study confirm that docetaxel AUC is significantly correlated with neutropenia, correlation of coefficient is 0.452 , which is consistent with previous findings $(2,14-21)$. We pre-set an optimal AUC range for Asian populations according to pooled analysis of several $\mathrm{PK}$ and toxicity researches $(5,15-21)$. The optimal AUC range was preset to $2.5-3.7 \mu \mathrm{g} \cdot \mathrm{hr} / \mathrm{mL}$ to minimize the rate of severe neutropenia, which is verified in our study. Patients over-exposed (AUC above $3.7 \mu \mathrm{g} \cdot \mathrm{hr} / \mathrm{mL}$ ) to docetaxel experienced significant higher grade 3-4 and grade 4 neutropenia, the upper limit of target is successfully verified. Efficacy analysis shows no significant relationship was found between AUC and objective response rate, no difference between responders and non-responders neither. There results suggested that docetaxel at the dosage of $60 \mathrm{mg} / \mathrm{m}^{2}$ is probably still overdosed for East Asian population. Lower limit set at $2.5 \mu \mathrm{g} \cdot \mathrm{hr} / \mathrm{mL}$ would not damage the treatment efficacy in the first place, and closed to the median value $(2.58 \mu \mathrm{g} \cdot \mathrm{hr} / \mathrm{mL})$ to ensure dose intensity. This therapeutic range of docetaxel AUC might fit the therapeutic dose monitoring (TDM) attempt in future studies for Chinese patients.

The major obstacle for cytotoxic drug is the unexpected toxicity caused by large inter-individual variability of drug exposure (12-14). Traditional BSA based dosing method has limited contribution for reducing inter-individual variability.
For patients over-exposed to docetaxel, severe toxicity is one of the reasons for early discontinued treatment. Patients under-exposed to the drug rarely require doses to be increased to achieve an intra-patient maximum tolerated dose (MTD). Such dose escalations are difficult to execute in practice due to concerns over the potential to cause severe side effects. Using AUC based TDM to minimize toxicity or achieve better efficacy is a promising direction of cytotoxic drug research (40). Gamelin's researches indicated that the therapeutic range of 5 -fluorouracil (5-FU) for colorectal cancer patients is $20-25 \mathrm{mg} \cdot \mathrm{hr} / \mathrm{L}$, dose adjustment according to this range will significantly improve 5-FU efficacy and reduce incident rate of diarrhea (41). Joerger's researches also indicated paclitaxel exposure (Tc $>0.05$, time above a plasma concentration of $0.05 \mu \mathrm{M}$ ) is related with its toxicity and efficacy, Tc $>0.05$ between 26-31 hours should be set as the target range. The results of a randomized phase III trial show that dosing according to the target range could significant reduce paclitaxelassociated neuropathy (42). In order to accomplish this goal, a target AUC range must be established. Before the randomized phase III trial of 5-FU in colorectal cancer, Gamelin had launched several PK studies using weekly 8 hours continuous infusion or 5-FU, the results showed a relationship of AUC and both efficacy and toxicity of treatment. An $\mathrm{AUC}_{0-8}$ of 20 to $25 \mathrm{mg} \cdot \mathrm{hr} / \mathrm{L}$ as the optimal 
level (43). Joerger also using pooled data to conclude that Tc $>0.05$ was the ideal candidate for TDM, which was significantly correlated with paclitaxel-related absolute neutrophil count nadir. A prospective trial was proposed and verified that target range of Tc $>0.05$ was $26-31$ hours and individual dosing accordingly would significantly reduce grade 4 neutropenia (44). As to docetaxel, AUC was proved an effective metric for TDM (5,15-21). Engels reported a randomized PK study of TDM for the individualization of docetaxel dosing in Caucasian population. The target of AUC was set at 3.68 and $4.90 \mathrm{ug} \cdot \mathrm{hr} / \mathrm{mL}$ for 75 and $100 \mathrm{mg} / \mathrm{m}^{2}$, respectively. Dosing guided by this target, the inter-individual variability of AUC was reduced by $35 \%$, so was percentage decrease in white blood cell and absolute neutrophil count variability. In our study, due to the small sample size (39 patients enrolled) and lack of docetaxel PK data in East Asian population. So, it's more appropriate to analyze AUC data and toxicity or efficacy data and establish a preliminary target AUC range according to previous similar docetaxel PK studies, and further verify this target in our study. Lower AUC might further reduce the incident rate of grade 3-4 neutropenia, but it might also damage the efficacy which requires larger sample size to confirm. So, the lower limit of the range was decided at $2.5 \mu \mathrm{g} \cdot \mathrm{hr} / \mathrm{mL}$ to ensure adequate dose intensity. Our data suggest this AUC range in Chinese head and neck patients receiving docetaxel based chemotherapy is reliable and may be verified and utilized in future randomized clinical trials of TDM. Further prospective PK studies are needed to verify that target AUC range.

\section{Conclusions}

Our study suggested a target docetaxel AUC (2.5-3.7 $\mu \mathrm{g} \cdot \mathrm{hr} / \mathrm{mL})$ for Chinese head and neck patients receiving docetaxel based chemotherapy. Patients with an AUC within the target range, severe toxicity can be statistically reduced without compromising efficacy. Sampling at EOI and about $1 \mathrm{~h}$ after introduces slight but acceptable bias in the AUC calculation compared to full sampling.

Current study included patients received cisplatin and 5-Fu triplet chemotherapy. These drugs could have a proportion of influences on neutropenia which is considered invariant. Instead of launching a large scale phase II trial to conclude the target AUC range, we chose to preset a range from literature review and verified it in a small sample size prospective phase II trial. The estimated optimal AUC range was mainly based on toxicity data. So, this target range should be further validated in a prospective randomized clinical trial.

\section{Acknowledgments}

We thank the patients and their families for contributing to this study.

Funding: This work was supported by Medical Scientific Research Foundation of Guangdong Province of China (A2018010 to Y Ma); and National Nature Science Foundation of China [81572659 to W Fang, 81602011 to Y Yang].

\section{Footnote}

Conflicts of Interest: The authors have no conflicts of interest to declare.

Ethical Statement: The authors are accountable for all aspects of the work in ensuring that questions related to the accuracy or integrity of any part of the work are appropriately investigated and resolved. The study was approved by the Ethical Committee of Sun Yat-Sen University Cancer Center (B2013-008-01). Informed consent written informed consent was obtained from all participating subjects. This trial was registered at clinicaltrials.gov (NCT01891123).

Open Access Statement: This is an Open Access article distributed in accordance with the Creative Commons Attribution-NonCommercial-NoDerivs 4.0 International License (CC BY-NC-ND 4.0), which permits the noncommercial replication and distribution of the article with the strict proviso that no changes or edits are made and the original work is properly cited (including links to both the formal publication through the relevant DOI and the license). See: https://creativecommons.org/licenses/by-nc-nd/4.0/.

\section{References}

1. Taxotere Package insert. Aventis Pharmaceuticals Inc., 2003 Rev April.

2. Walko CM, McLeod H. Pharmacogenomic progress in individualized dosing of key drugs for cancer patients. Nat Clin Pract Oncol 2009;6:153-62.

3. Mathijssen RH, Sparreboom A, Verweij J. Determining the optimal dose in the development of anticancer agents. Nat Rev Clin Oncol 2014;11:272-81. 
4. Baker SD, Li J, ten Tije AJ, et al. Relationship of systemic exposure to unbound docetaxel and neutropenia. Clin Pharmacol Ther 2005;77:43-53.

5. Minami H, Kawada K, Sasaki Y, et al. Pharmacokinetics and pharmacodynamics of protein-unbound docetaxel in cancer patients. Cancer Sci 2006;97:235-41.

6. Schöffski P, Catimel G, Planting AS, et al. Docetaxel and cisplatin: an active regimen in patients with locally advanced, recurrent or metastatic squamous cell carcinoma of the head and neck. Results of a phase II study of the EORTC Early Clinical Studies Group. Ann Oncol 1999;10:119-22.

7. Colevas AD, Posner MR. Docetaxel in head and neck cancer: a review. Am J Clin Oncol 1998;21:482-6.

8. Reilly JJ, Workman P. Normalisation of anti-cancer drug dosage using body weight and surface area: is it worthwhile? A review of theoretical and practical considerations. Cancer Chemother Pharmacol 1993;32:411-8.

9. Felici A, Verweij J, Sparreboom A. Dosing strategies for anticancer drugs: the good, the bad and body-surface area. Eur J Cancer 2002;38:1677-84.

10. Freireich EJ, Gehan EA, Rall DP, et al. Quantitative comparison of toxicity of anticancer agents in mouse, rat, hamster, dog, monkey, and man. Cancer Chemother Rep 1966;50:219-44.

11. Rudek MA, Sparreboom A, Garrett-Mayer ES, et al. Factors affecting pharmacokinetic variability following doxorubicin and docetaxel-based therapy. Eur J Cancer 2004;40:1170-8.

12. Undevia SD, Gomez-Abuin G, Ratain MJ. Pharmacokinetic variability of anticancer agents. Nat Rev Cancer 2005;5:447-58.

13. Paci A, Veal G, Bardin C, et al. Review of therapeutic drug monitoring of anticancer drugs part 1--cytotoxics. Eur J Cancer 2014;50:2010-9.

14. Alnaim L. Therapeutic drug monitoring of cancer chemotherapy. J Oncol Pharm Pract 2007;13:207-21.

15. Extra JM, Rousseau F, Bruno R, et al. Phase I and pharmacokinetic study of Taxotere (RP 56976; NSC 628503 ) given as a short intravenous infusion. Cancer Res 1993;53:1037-42.

16. Bruno R, Hille D, Riva A, et al. Population pharmacokinetics/pharmacodynamics of docetaxel in phase II studies in patients with cancer. J Clin Oncol 1998;16:187-96.

17. Goh BC, Lee SC, Wang LZ, et al. Explaining interindividual variability of docetaxel pharmacokinetics and pharmacodynamics in Asians through phenotyping and genotyping strategies. J Clin Oncol 2002;20:3683-90.

18. Baker SD, Zhao M, Lee CK, et al. Comparative pharmacokinetics of weekly and every-three-weeks docetaxel. Clin Cancer Res 2004;10:1976-83.

19. ten Tije AJ, Verweij J, Carducci MA, et al. Prospective evaluation of the pharmacokinetics and toxicity profile of docetaxel in the elderly. J Clin Oncol 2005;23:1070-7.

20. Ozawa K, Minami H, Sato H. Logistic regression analysis for febrile neutropenia $(\mathrm{FN})$ induced by docetaxel in Japanese cancer patients. Cancer Chemother Pharmacol 2008;62:551-7.

21. Engels FK, Loos WJ, van der Bol JM, et al. Therapeutic drug monitoring for the individualization of docetaxel dosing: a randomized pharmacokinetic study. Clin Cancer Res 2011;17:353-62.

22. Kenmotsu H, Tanigawara Y. Pharmacokinetics, dynamics and toxicity of docetaxel: Why the Japanese dose differs from the Western dose. Cancer Sci 2015;106:497-504.

23. Ozawa K, Minami H, Sato H. Population pharmacokinetic and pharmacodynamic analysis for time courses of docetaxel-induced neutropenia in Japanese cancer patients. Cancer Sci 2007;98:1985-92.

24. Baille P, Bruno R, Schellens JH, et al. Optimal sampling strategies for bayesian estimation of docetaxel (Taxotere) clearance. Clin Cancer Res 1997;3:1535-8.

25. Cline DJ, Zhang H, Lundell GD, et al. An automated nanoparticle-based homogeneous immunoassay for determining docetaxel concentrations in plasma. Ther Drug Monit 2013;35:803-8.

26. Bosch TM, Huitema AD, Doodeman VD, et al. Pharmacogenetic screening of CYP3A and ABCB1 in relation to population pharmacokinetics of docetaxel. Clin Cancer Res 2006;12:5786-93.

27. Lewis LD, Miller AA, Rosner GL, et al. A comparison of the pharmacokinetics and pharmacodynamics of docetaxel between African-American and Caucasian cancer patients: CALGB 9871. Clin Cancer Res 2007;13:3302-11.

28. Hooker AC, Ten Tije AJ, Carducci MA, et al. Population pharmacokinetic model for docetaxel in patients with varying degrees of liver function: incorporating cytochrome P4503A activity measurements. Clin Pharmacol Ther 2008;84:111-8.

29. Zamboni WC, Combest AJ, DeLoia JA, et al. Pharmacologic and phenotypic study of docetaxel in patients with ovarian or primary peritoneal cancer. Cancer Chemother Pharmacol 2011;68:1255-62.

30. Nieuweboer AJ, Smid M, de Graan AM, et al. Role of 
genetic variation in docetaxel-induced neutropenia and pharmacokinetics. Pharmacogenomics J 2016;16:519-24.

31. Kenmotsu H, Imamura CK, Ono A, et al. The effects of advanced age and serum $\alpha 1$-acid glycoprotein on docetaxel unbound exposure and dose-limiting toxicity in cancer patients. Br J Clin Pharmacol 2017;83:2416-25.

32. Fukae M, Shiraishi Y, Hirota T, et al. Population pharmacokinetic pharmacodynamic modeling and modelbased prediction of docetaxel-induced neutropenia in Japanese patients with non-small cell lung cancer. Cancer Chemother Pharmacol 2016;78:1013-23.

33. van Hasselt JG, van Calsteren K, Heyns L, et al. Optimizing anticancer drug treatment in pregnant cancer patients: pharmacokinetic analysis of gestation-induced changes for doxorubicin, epirubicin, docetaxel and paclitaxel. Ann Oncol 2014;25:2059-65.

34. Lévy P, Gligorov J, Antoine M, et al. Influence of ABCB1 polymorphisms and docetaxel pharmacokinetics on pathological response to neoadjuvant chemotherapy in breast cancer patients. Breast Cancer Res Treat 2013;139:421-8.

35. Fujita K, Yoshino E, Kawara K, et al. A clinical pharmacokinetic microdosing study of docetaxel with Japanese patients with cancer. Cancer Chemother Pharmacol 2015;76:793-801.

36. Minami H, Kawada K, Sasaki Y, et al. Population pharmacokinetics of docetaxel in patients with hepatic dysfunction treated in an oncology practice. Cancer Sci 2009;100:144-9.

37. Syn NL, Wang L, Wong AL, et al. Dose modifications in Asian cancer patients with hepatic dysfunction receiving weekly docetaxel: A prospective pharmacokinetic and safety study. Cancer Sci 2016;107:173-80.

38. Chew SC, Lim J, Singh O, et al. Pharmacogenetic effects of regulatory nuclear receptors (PXR, CAR,

Cite this article as: Ma Y, Lin Q, Yang Y, Liang W, Salamone SJ, Li Y, Lin Y, Zhao H, Zhao Y, Fang W, Huang Y, Zhang L. Clinical pharmacokinetics and drug exposure-toxicity correlation study of docetaxel based chemotherapy in Chinese head and neck cancer patients. Ann Transl Med 2020;8(5):236. doi: $10.21037 /$ atm.2020.01.76
$\mathrm{RXR} \alpha$ and $\mathrm{HNF} 4 \alpha$ ) on docetaxel disposition in Chinese nasopharyngeal cancer patients. Eur J Clin Pharmacol 2014;70:155-66.

39. Chew SC, Singh O, Chen X, et al. The effects of CYP3A4, CYP3A5, ABCB1, ABCC2, ABCG2 and SLCO1B3 single nucleotide polymorphisms on the pharmacokinetics and pharmacodynamics of docetaxel in nasopharyngeal carcinoma patients. Cancer Chemother Pharmacol 2011;67:1471-8.

40. de Jonge ME, Huitema AD, Schellens JH, et al. Individualised cancer chemotherapy: strategies and performance of prospective studies on therapeutic drug monitoring with dose adaptation: a review. Clin Pharmacokinet 2005;44:147-73.

41. Gamelin E, Jacob J, Merrouche Y, et al. Individual 5 -fluorouracil dose adjustment based on pharmacokinetic follow-up compared with conventional dosage: results of a multicenter randomized trial in patients with metastatic colorectal cancer. J Clin Oncol 2008;26:2099-105.

42. Joerger M, von Pawel J, Kraff S, et al. Open-label, randomized study of individualized, pharmacokinetically (PK)-guided dosing of paclitaxel combined with carboplatin or cisplatin in patients with advanced non-small-cell lung cancer (NSCLC). Ann Oncol 2016;27:1895-902.

43. Gamelin E, Boisdron-Celle M. Dose monitoring of 5-fluorouracil in patients with colorectal or head and neck cancer: Status of the art. Crit Rev Oncol Hematol 1999;30:71-9.

44. Joerger M, Kraff S, Huitema AD, et al. Evaluation of a pharmacology-driven dosing algorithm of 3-weekly paclitaxel using therapeutic drug monitoring: a pharmacokinetic pharmacodynamic simulation study. Clin Pharmacokinet 2012;51:607-17. 